\title{
Successful Management of Infertile Patient with Trans-Fundal Uterine Membrane
}

\author{
Reda Alami, MD, ${ }^{1}$ John Hebert, MD,,2 Mohammad Ashraf, MD, ${ }^{1-3}$ and Mostafa Abuzeid, MD ${ }^{1-3}$
}

\begin{abstract}
Background: This case report describes an infertile patient with a rare endometrial cavity pathology diagnosed on hysteroscopy. Case: The patient was a 39-year-old female with primary infertility of 9 years' duration. A diagnosis of a possible T-shaped uterus on a previous hysterosalpingogram was not confirmed on diagnostic hysteroscopy 5 years earlier at a different infertility center, where she had undergone a cycle of in-vitro fertilization with embryo transfer (IVF-ET) but was unable to conceive. At the time of diagnostic hysteroscopy at the current, unit the patient was found to have a T-shaped cavity and a trans-fundal uterine membrane obscuring an arcuate fundus. Hysteroscopic division of this thin membrane was performed successfully, followed by hysteroscopic division of the uterine septum and hysteroscopic metroplasty of her T-shaped uterus. Results: Subsequently, the patient conceived with IVF-ET but had an early miscarriage. A second IVF-ET cycle resulted in resulted in delivery of a healthy male infant at term. Conclusions: This report described a case of an infertile patient with a trans-fundal membrane in association with a uterine anomaly. The discovery of such a membrane and the uterine anomaly described above, and their hysteroscopic surgical correction, may have contributed to the successful reproductive outcome for this patient. (J GYNECOL SURG 29:88)
\end{abstract}

\section{Introduction}

C ONGENITAL UTERINE ANOMALIES have been estimated to affect $0.06 \%-10 \%$ of women. ${ }^{1,2}$ Incidence in patients with primary infertility is estimated to be between $0.5 \%$ and $26 \%{ }^{3-5}$ A normal endometrial cavity is essential for an optimal reproductive outcome. ${ }^{6}$ Uterine abnormalities contribute to recurrent pregnancy losses, poor pregnancy outcomes, and, what has been realized more recently, problems with infertility. ${ }^{2,6-8}$ Obvious pathology in the endometrial cavity (e.g., a complete uterine septum) is easy to diagnose, while subtle pathology can sometimes be difficult to diagnose.

\section{Case}

The patient discussed in this report was a 39-year-old Asian female who presented to the infertility clinic for evaluation of primary infertility of 9 years' duration. Her past medical history was remarkable for adult-onset diabetes mellitus since 2003, which was well-controlled with insulin and metformin. At age 35, a hysterosalpingogram (HSG) as part of an evaluation for her infertility at a different infertility clinic suggested that she had a T-shaped uterus and patent fallopian tubes. However, a subsequent diagnostic hysteroscopy suggested that she had a normal endometrial cavity. This patient had irregular periods and was diagnosed with polycystic ovarian syndrome (PCOS), for which she was treated with clomiphene citrate for five cycles without success. She had undergone one cycle of in-vitro fertilization with embryo transfer (IVF/ET) but was unable to conceive.

In view of the multiple infertility factors, which included her advanced female reproductive age and her long-term duration of infertility, this patient was offered IVF-ET treatment. A saline sonohysterogram with both two-dimensional (2D) and three-dimensional (3D) ultrasound (US) were performed prior to the IVF treatment. The 3D US suggested that she had a T-shaped uterus. IVF-ET was then performed; unfortunately, the patient did not conceive. At that stage, the patient was offered a review hysteroscopy to evaluate her endometrial cavity before any further attempts at IVF-ET. A diagnostic hysteroscopy revealed an arcuate appearance of the fundal region (Fig. 1) and a T-shaped cavity. Using a straight monopolar resectoscope loop with a cutting current

\footnotetext{
${ }^{1}$ Department of Obstetrics and Gynecology, Hurley Medical Center, Flint, MI.

${ }^{2}$ Department of Obstetrics and Gynecology and Reproductive Biology, College of Human Medicine, Michigan State University, Flint Campus, Flint, MI.

${ }^{3}$ IVF Michigan, PC, Flint, MI, and Rochester Hills, MI.

Presented at the American Association of Gynecologic Laparoscopists (AAGL) 37th Global Congress of Minimally Invasive Gynecology, Las Vegas, NV, October 31, 2008. In: J Minim Invasive Gynecol 2008;15(6suppl):S-51;abstract No. 201.
} 


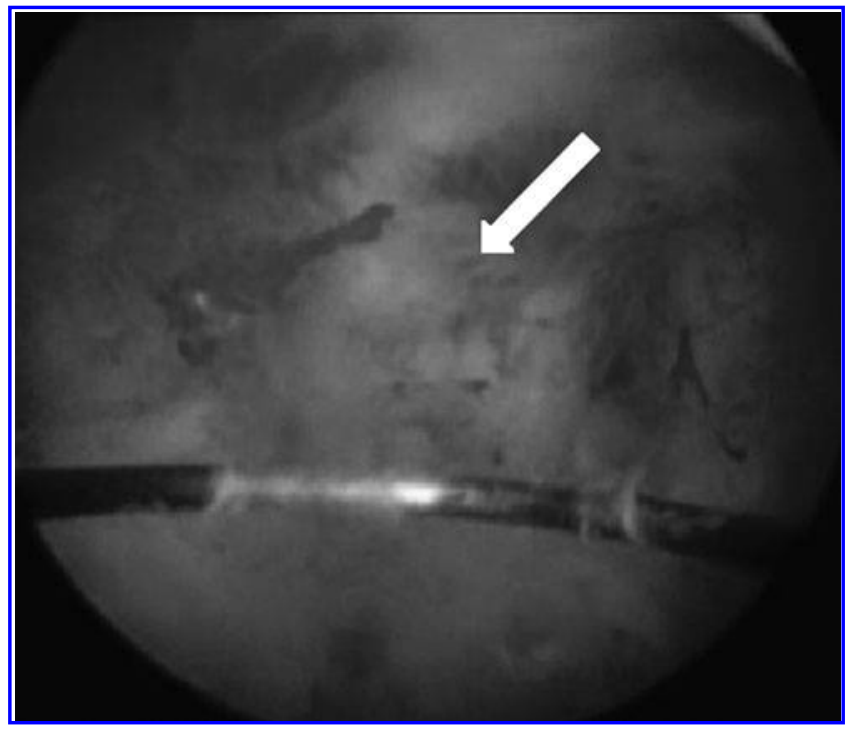

FIG. 1. Hysteroscopic picture depicting an arcuate appearance of the fundal region of the uterus (arrow) before the start of the surgical procedure.

of 70 Watts, division of the short uterine septum in the fundal region was performed. Care was taken to work at equal distance from both the anterior and posterior walls. After cutting through the first part in the middle of the segment, a hole was noticed (Fig. 2), and some turbid fluid was seen coming from an area above the hole. This hole had a cavity above it leading to the uterine fundus. The next step was to incise what was thought to be a thin membrane that was transversely stretched between the two uterine cornua. Upon completing this step the uterine fundus became visible and this revealed an arcuate uterus. The short uterine septum was divided easily, using a straight monopolar resectoscope loop with a cutting current of 70 Watts, without any prob-

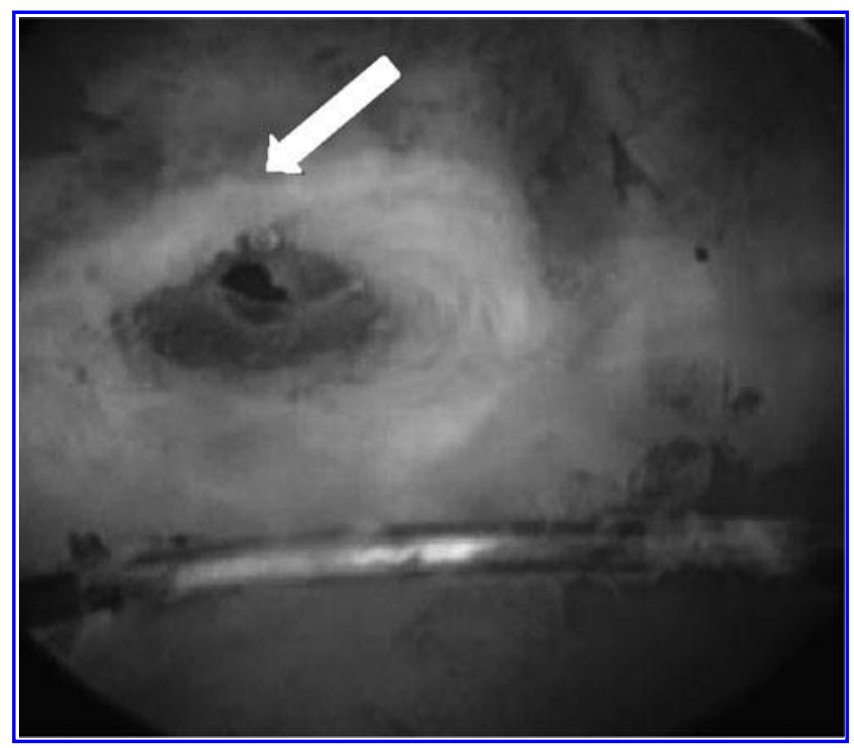

FIG. 2. Hysteroscopic picture depicting a hole in a transfundal membrane (arrow) that was obscuring the uterine fundus.

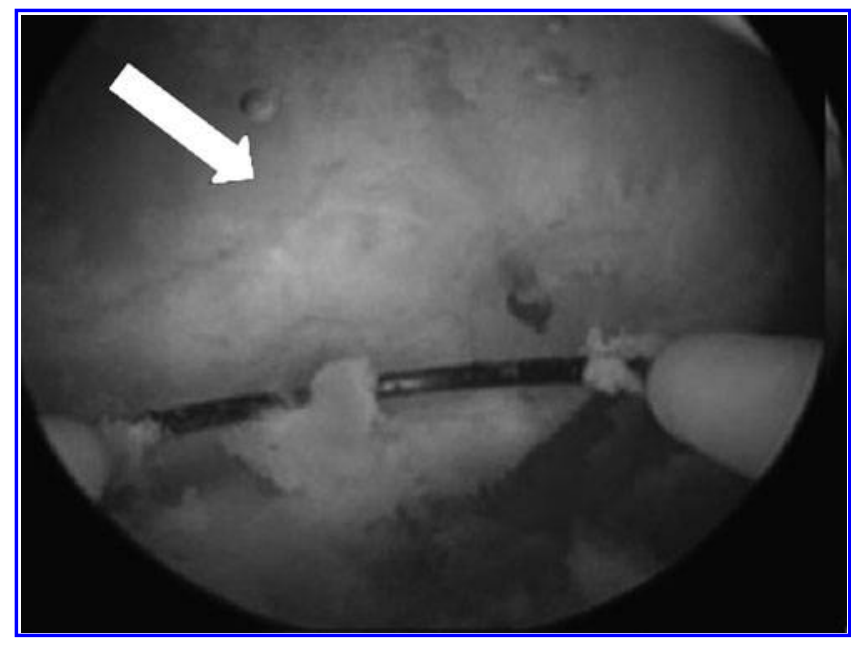

FIG. 3. Hysteroscopic picture depicting the fundus of the uterine cavity (arrow) after the trans-fundal membrane was incised and the arcuate fundus was divided.

lems (Fig. 3). The T-shaped cavity was confirmed (Fig. 4), and hysteroscopic metroplasty was performed by incising the lateral uterine-wall ridges, using a monopolar resectoscope loop with a curved needle tip and using a cutting current of 70 Watts. Upon completing the procedure both tubal ostia became visible. Hemostasis was ensured. At the end of the procedure, a pediatric Foley catheter ( 8 French) was introduced into the uterine cavity and the catheter balloon was inflated with $3 \mathrm{cc}$ of normal saline. The catheter was removed after 10 days. The patient was placed on exogenous estrogen for 6 weeks followed by progestin for 10 days.

\section{Results}

Subsequently, saline sonohysterograms (both 2D and 3D US) revealed a normal endometrial cavity. The postoperative period was uneventful. Three months later, IVF/ET was attempted. The patient conceived but had an early miscarriage.

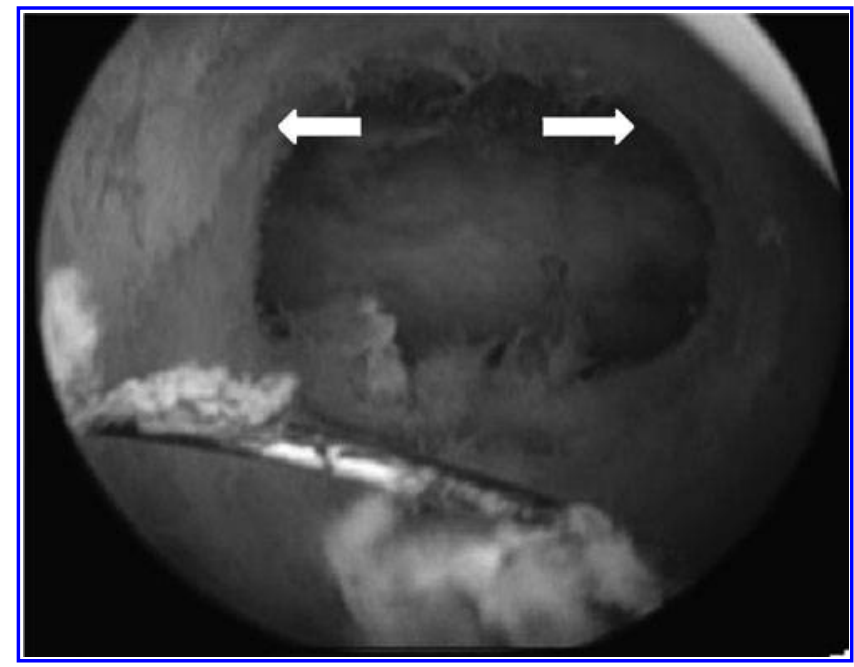

FIG. 4. Hysteroscopic picture with arrows pointing toward the lateral walls of a T-shaped cavity before hysteroscopic surgical correction of the lateral walls. 
Following a second IVF/ET cycle, the patient conceived and delivered a healthy male infant at full-term.

\section{Discussion}

Patients with uterine anomalies have increased chances of spontaneous and recurrent miscarriages, intrauterine growth restriction (IUGR), preterm labor, preterm delivery, and infertility. ${ }^{2,6-8}$ Uterine septum and arcuate uterus are the most common uterine anomalies, accounting for 34\% and 33\%, respectively. ${ }^{5,9}$ Therefore, a comprehensive evaluation of the endometrial cavity is important to identify any abnormalities that may affect reproductive outcomes. ${ }^{4}$ The goal of management is to achieve a normal uterine architecture if the uterine anomaly can be repaired (e.g., uterine septum and arcuate uterus). Over the last 3 decades, hysteroscopic division of the uterine septum has replaced the transabdominal approach and has been shown to be safe and effective, as well as significantly improving subsequent reproductive outcomes. ${ }^{10}$

Controversy still exists regarding the management of patients with T-shaped uteri. Many reproductive surgeons advocate no treatment, citing the fact that some patients with T-shaped uteri have favorable reproductive outcomes. However, over the past 2 decades, hysteroscopic metroplasty for T-shaped uteri has been advocated by some researchers with promising results. ${ }^{11}$ The patient described in this case report had two failed IVF-ET cycles, and she was running out of time in view of her reproductive age. What complicated the management of this patient was the fact that she had a hysteroscopy that was reported to show normal results, despite the finding on her HSG. This point highlights an important issue regarding the interpretation of various diagnostic procedures, including the "gold standard" for diagnosis of uterine anomalies (i.e., diagnostic hysteroscopy).

The successful outcome of treatment of this patient was most probably secondary to correction of the T-shaped cavity, short uterine septum, and, most importantly, the discovery and correction of this subtle uterine pathology in the form of a trans-fundal uterine membrane. The current authors believe that this membrane was not a healthy site for embryo implantation.

\section{Conclusions}

Hysteroscopy by an experienced individual is a reliable diagnostic tool for evaluating uterine-cavity abnormalities. Hysteroscopic correction of subtle endometrial-cavity pathology reduces implantation failure and enhances chances for better reproductive outcomes.

\section{Acknowledgments}

The authors would like to thank Cheryl Anderson for the preparation of the manuscript.

\section{Disclosure Statement}

The authors, Reda Alami, MD, John Hebert, MD, Mohammad Ashraf, MD and Motafa Abuzeid, MD, have no commercial, proprietary, or financial interest in the products or companies described in this article.

\section{References}

1. Kormanyos Z, Molnar BG, Pal A. Removal of a residual portion of a uterine septum in women of advanced reproductive age: Obstetric outcome. Hum Reprod 2006; 21:1047.

2. Hickok LR. Hysteroscopic treatment of the uterine septum: A clinician's experience. Am J Obstet Gynecol 2000;182: 1414.

3. Hinckley MD, Milki A. 1000 office-based hysteroscopies prior to in vitro fertilization: Feasibility and findings. $\underline{\text { Soc }}$ Lap Surg 2004;8:103.

4. Abuzeid M, Sakhel K, Ashraf M, Miteally MF, Diamond MP. The association between uterine septum and infertility. Fert Steril 2005;84(suppl1):S472.

5. Raga F, Bauset C, Remohi J, Bonilla-Musoles F, Simón C, Pleicer A. Reproductive impact of congenital Müllerian anomalies. Hum Reprod 1997;10:2277.

6. Kupesic S, Kurjak A, Skendrovic S, Bjelos D. Screening for uterine abnormalities by three-dimensional ultrasound improves perinatal outcome. J Perinat Med 2002;30:9.

7. Rama Raju GA, Shashi Kumari G, Krishna KM, Prakash GJ, Madan K. Assessment of uterine cavity by hysteroscopy in assisted reproduction programme and its influence on pregnancy outcome. Arch Gynecol Obstet 2006; 274:160.

8. Pabuccu R, Gomal V. Reproductive outcome after hysteroscopic metroplasty in women with septate uterus and otherwise unexplained infertility. Fert Steril 2004;81:1677.

9. Nahum GG. Uterine anomalies: How common are they, and what is their distribution among subtypes? J Reprod Med 1998;43:877.

10. Venturoli S, Colombo FM, Vianello F, Seracchioli R, Possati G, ParadisiR. A study of hysteroscopic metroplasty in 141 women with a septate uterus. Arch Gynecol Obstet 2002; 266:157.

11. Fernandez H, Garbin O, Castaigne V, Gervaise A, Levaillant JM. Surgical approach to and reproductive outcome after surgical correction of a T-shaped uterus. Hum Reprod 2011;26:1730.

Address correspondence to: Mostafa Abuzeid, MD Hurley Medical Center

Two Hurley Plaza, Suite 209 Flint, MI 48504

E-mail: reprod1@hurleymc.com 